\title{
Renal Potassium Wasting in Renal Tubular Acidosis (RTA)
}

\author{
ITS OCCURRENCE IN TYPES 1 AND 2 RTA DESPITE \\ SUSTAINED CORRECTION OF SYSTEMIC ACIDOSIS
}

\author{
Anthony Sebastian, Elisabeth McSherry, and R. Curtis Morris, Jr. \\ From the Departments of Medicine and Pediatrics, University of California, \\ San Francisco, California 94122
}

A B S T R A C T In two patients with classic renal tubular acidosis (RTA) and in two patients with RTA associated with the Fanconi syndrome, renal potassium wasting persisted despite sustained correction of acidosis: (a) during moderate degrees of hypokalemia, daily urinary excretion of potassium exceeded $80 \mathrm{mEq}$ in each patient; $(b)$ during more severe degrees of hypokalemia, daily urinary excretion of potassium exceeded $40 \mathrm{mEq}$ in two patients and $100 \mathrm{mEq}$ in another. These urinary excretion rates of potassium are more than twice those observed in potassium-depleted normal subjects with even minimal degrees of hypokalemia. The persistence of renal potassium wasting may have resulted in part from hyperaldosteronism, since urinary aldosterone was frankly increased in two patients and was probably abnormally high in the others relative to the degree of their potassium depletion. The hyperaldosteronism persisted despite sustained correction of acidosis, a normal sodium intake, and no reduction in measured plasma volume, and was not associated with hypertension; its cause was not defined. In the two patients with classic RTA, neither renal potassium wasting nor hyperaldosteronism could be explained as a consequence of a gradient restriction on renal $\mathrm{H}^{+}-\mathrm{Na}^{+}$exchange because the urinary $\mathrm{pH}$ remained greater than, or approximately equal to, the normal arterial $\mathrm{pH}$ or considerably greater than the minimal urinary $\mathrm{pH}$ attained during acidosis. The findings provide no support for the traditional view that renal potassium wasting in either classic RTA or RTA

This work was presented in part at the Annual Meeting of the American Society of Nephrology, Washington, D. C., November 1968.

Dr. Sebastian and Dr. McSherry were recipients of Bank of America-Giannini Foundation Fellowships. Dr. McSherry is currently recipient of an NIH Special Fellowship 5F03HD41889.

Received for publication 28 April 1970 and in revised form 13 November 1970. associated with the Fanconi syndrome is predictably corrected solely by sustained correction of acidosis with alkali therapy.

\section{INTRODUCTION}

Renal tubular acidosis (RTA) is a syndrome of disordered renal acidification characterized biochemically by minimal or no azotemia, hyperchloremic acidosis, an inappropriately high urinary $\mathrm{pH}$, bicarbonaturia, and reduced urinary excretion rates of titratable acid and ammonium (1-6). According to current views $(7,8)$, this syndrome can reflect two physiologically distinct disorders of renal acidification: In patients with classic RTA (type 1 RTA, "distal" or "gradient" RTA), the urinary $\mathrm{pH}$ is inappropriately high during severe as well as mild degrees of acidosis and persisting bicarbonaturia is characteristic. The amount of bicarbonate excreted, however, is a trivial fraction of that filtered at normal as well as subnormal plasma bicarbonate concentrations, a finding indicating no substantial reduction in the rate at which the proximal (or distal) nephron reabsorbs bicarbonate $(4,6)$. In contrast, in patients with RTA associated with the Fanconi syndrome (type 2 RTA, "proximal" or "rate" RTA), the amount of bicarbonate excreted at normal plasma bicarbonate concentrations is more than $15 \%$ of that filtered, a finding indicating that the rate of bicarbonate reabsorption in the proximal nephron is reduced (9). Prototypically, the urine $\mathrm{pH}$ is inappropriately high, and bicarbonaturia occurs, only during moderate or mild degrees of acidosis; during more severe degrees of acidosis, bicarbonaturia disappears, urinary $\mathrm{pH}$ decreases to normal minima, and acid excretion is not reduced $(9,10)$.

${ }^{1}$ Abbreviations used in this paper: RTA, renal tubular acidosis. 
Renal potassium wasting commonly occurs in both types of RTA $(1-4,11-14)$, and in both has been inferred to be a reversible consequence of the renal acidification disorder $(1,4,6,14-18)$. In patients with classic RTA, this inference is based on the observation that correction of systemic acidosis with alkali therapy can lead to a reduction in urinary excretion of potassium and correction of hypokalemia $(1,2,18)$. In patients with RTA as part of the Fanconi syndrome, a similar response to corrective alkali therapy has been assumed (17) but apparently never demonstrated $(3,11,12)$.

In the presently reported studies of two patients with classic RTA and of two patients with RTA associated with the Fanconi syndrome, renal potassium wasting was observed to persist despite sustained correction of systemic acidosis with alkali therapy: In each patient, urinary excretion of potassium exceeded $80 \mathrm{mEq}$ per day in the face of persisting hypokalemia, and each patient required more than the usual dietary intake of potassium to maintain normokalemia. These results indicate that in patients with either classic RTA or RTA associated with the Fanconi syndrome, correction of acidosis cannot be predicted to correct renal potassium wasting.

\section{METHODS}

A total of six modified balance studies were performed on four patients with RTA (two with classic RTA and two with RTA associated with the Fanconi syndrome), specifically selected for study because hypokalemia persisted during sustained correction of acidosis despite normal or even supernormal potassium intake. In each study, renal conservation of potassium was examined during potassium depletion evidenced by hypokalemia in the absence of alkalosis. In five studies (studies 1-5), which included at least one study of each patient, correction of systemic acidosis was sustained throughout with alkali therapy. In studies 1-4 (M. P., R. G., L. C. S., L. C. S., respectively), hypokalemia was produced by reducing the patient's oral potassium supplement; in the study on M. P. and in one study on L. C. S. (study 3), all potassium supplements were discontinued. In studies 5 (K. E.) and 6 (L. C. S.), hypokalemia was present throughout. In the sixth study (L.C.S.), $\mathrm{NaHCO}_{3}$ was administered in gradually increasing amounts such that acidosis was corrected by the smallest amount possible.

Throughout each study period and for 5 days before, each patient ingested a constant diet of known electrolyte composition, which provided at least $85 \mathrm{mEq}$ of sodium and 50 $\mathrm{mEq}$ of potassium daily (M. P., R. G., K. E.) or in the smallest patient (L.C.S.), whose weight was less than 40 $\mathrm{kg}, 2 \mathrm{mEq} / \mathrm{kg}$ of sodium and $1.0 \mathrm{mEq} / \mathrm{kg}$ of potassium daily. In all but study 6 , the patients were receiving oral potassium supplements and bicarbonate when the studies were begun, and had not been acidotic for at least 2 months previously.

Blood samples were drawn in the morning before breakfast, at least $4 \mathrm{hr}$ after the last dose of bicarbonate or supplemental potassium. Serum sodium, potassium, chloride, and creatinine concentrations, and serum carbon dioxide content were determined on venous blood; blood $\mathrm{pH}$ and carbon dioxide tension were determined on arterialized blood drawn from a superficial vein on the back of the hand, that had been heated with an electric heating muffler to at least $45^{\circ} \mathrm{C}$ for more than $60 \mathrm{~min}$. Urine was collected under a layer of mineral oil in 24-hr pools, preserved with thymol, and refrigerated until the $\mathrm{pH}$ and carbon dioxide content were determined, usually within $24 \mathrm{hr}$; the concentrations of sodium, potassium, chloride, and creatinine were measured subsequently.

Laboratory determinations were carried out as described previously $(9,19)$. Plasma volumes were determined by the ${ }^{181}$ I albumin dilution technique.

TABLE I

Clinical and Physiologic Data in Patients with Renal Tubular Acidosis (RTA)

\begin{tabular}{|c|c|c|c|c|c|c|c|c|c|}
\hline \multirow{2}{*}{$\begin{array}{l}\text { Patient, } \\
\text { age }(y r), \\
\text { and sex }\end{array}$} & \multirow[b]{2}{*}{ Clinical diagnosis } & \multirow[b]{2}{*}{$C_{\text {in }}$} & \multicolumn{3}{|c|}{ Urinary acidification* } & \multirow{2}{*}{$\begin{array}{c}\mathrm{THCO}_{3}^{-} \\
\text {(Plasma } \\
{\left[\mathrm{HCO}_{2}^{-}\right]} \\
25 \text { mmoles/ } \\
\text { liter) }\end{array}$} & \multirow{2}{*}{$\begin{array}{c}\text { Alkali } \\
\text { require- } \\
\text { ment } \ddagger\end{array}$} & \multicolumn{2}{|c|}{ Urinary excretion } \\
\hline & & & $\begin{array}{l}\mathrm{U}_{\mathrm{pH}} \min \\
\left(\mathrm{tCO}_{2}\right)\end{array}$ & UTAV $_{\text {TA }}$ & $\mathrm{UNH}_{4}+\mathrm{V}$ & & & $\underset{\mathrm{N}}{\alpha \text {-Amino }}$ & Glucose \\
\hline & & $\begin{array}{l}\mathrm{ml} / \mathrm{min} / \\
1.73 \mathrm{~m}^{2}\end{array}$ & \multicolumn{3}{|c|}{$\mu E q / \min$} & $\begin{array}{l}\text { mmoles } / 100 \\
\quad m l G F\end{array}$ & $\begin{array}{c}\text { mmoles/ } \\
\text { day }\end{array}$ & $m g / d a y$ & $g / d a y$ \\
\hline & Normal values & & $<5.31$ & $>25.0$ & $>39.0$ & 2.5 & & $50-150$ & \\
\hline L. C. S. 19, F & $\begin{array}{l}\text { Primary RTA (familial), } \\
\text { nephrocalcinosis }\end{array}$ & 89.3 & $\begin{array}{r}6.79 \\
(16.5)\end{array}$ & 7.7 & 23.1 & 2.4 & $60-110$ & 78 & $\mathbf{0}$ \\
\hline K. E. 22, F & $\begin{array}{l}\text { Lupoid hepatitis, classic } \\
\text { RTA, nephrocalcinosis }\end{array}$ & 82.1 & $\begin{array}{r}7.10 \\
(20.1)\end{array}$ & 4.3 & 16.4 & & $60-80$ & 67 & $\mathbf{0}$ \\
\hline M. P. 63, M & $\begin{array}{l}\text { Multiple myeloma, Fanconi } \\
\text { syndrome, RTA }\end{array}$ & 74.3 & $\begin{array}{r}5.83 \\
(14.0)\end{array}$ & 18.3 & 68.7 & 2.1 & $150-200$ & 333 & $\mathbf{0}$ \\
\hline R. G. 20, $\mathrm{M}$ & $\begin{array}{l}\text { Idiopathic Fanconi syn- } \\
\text { drome, RTA }\end{array}$ & 22.3 & $\begin{array}{r}5.24 \\
(15.3)\end{array}$ & 35.0 & 20.8 & 1.6 & $150-200$ & 640 & 3.2 \\
\hline
\end{tabular}

$\mathrm{C}_{\mathrm{in}}$, inulin clearance; $\mathrm{U}_{\mathrm{pHmin}}$, minimal urinary $\mathrm{pH}$ (numerals in parentheses indicate lowest measured serum total $\mathrm{CO}_{2}$ in mmoles/liter); $\mathrm{U}_{\mathrm{TA}} \mathrm{V}$ and $\mathrm{UNH}_{4}+\mathrm{V}$, rates of excretion of titratable acid and of ammonium, respectively; $\mathrm{T} \mathrm{HCO}-$, tubular reabsorption of bicarbonate; GF, glomerular filtrate.

* Response to existent or $\mathrm{NH}_{4} \mathrm{Cl}$-induced acidosis. Normal values establised in a previous study (20).

$\ddagger$ Total daily alkali requirement (administered orally in divided doses) necessary to maintain arterial plasma bicarbonate concentration in the range of 22-26 mmoles/liter. 


\section{RESULTS}

Table 1 summarizes clinical and physiologic data on the four patients.

Each of the four patients studied required continued supplements of potassium to maintain the serium potassium concentration at normal levels, despite a normal dietary intake of potassium and the absence of systemic acidosis or alkalosis. This requirement for potassium supplements was evidenced by the occurrence or worsening of hypokalemia when oral potassium supplements were reduced or discontinued (M. P., Fig. 1; R. G., Fig. 2; L. C. S., Fig. 3, Table II), or by the persistence of hypokalemia even when potassium supplements were continued (K. E., Table III). Before the potassium supplements were reduced, and the serum potassium concentration was stable and normal or near normal, urinary potassium excretion closely approximated potassium intake (Figs. 1-3, Table II). Accordingly, the requirement for supplemental potassium was not a consequence of extrarenal losses of potassium.

In all six studies, impaired renal conservation of potassium was documented. In studies $1-5$, in which arterial $\mathrm{pH}$ remained normal throughout (7.38-7.42), urinary potassium excretion was invariably greater than $40 \mathrm{mEq} /$ day and usually greater than $80 \mathrm{mEq} /$ day at serum potassium concentrations ranging from 3.2 to 3.8 $\mathrm{mEq} /$ liter (Figs. 1-4, Tables II and III). Since normal subjects experimentally depleted of potassium predictably excrete less than $40 \mathrm{mEq}$ of urinary potassium per day even with the most minimal degrees of hypokalemia (Fig. 4) (21-27), these findings indicate renal potassium wasting. In M. P. and L. C. S., urinary potassium excretion was greater than $40 \mathrm{mEq} /$ day even when the serum potassium concentration was less than $3.2 \mathrm{mEq} /$ liter (Figs. 1 and 3), and in K. E., urinary potassium excretion was consistently greater than $100 \mathrm{mEq} /$ day at serum potassium concentrations ranging from 2.6 to $3.3 \mathrm{mEq} /$ liter (Table III). These values of urinary potassium excretion are nearly twofold and approximately fourfold, respectively, the maximal values observed in normal subjects with comparable or even lesser degrees of hypokalemia (Fig. 4) (21-27).

In M. P. (Fig. 1), R. G. (Fig. 2), and L. C. S. (Fig. 3 , Table II), hypokalemia occurred rapidly when oral potassium supplements were reduced even though the

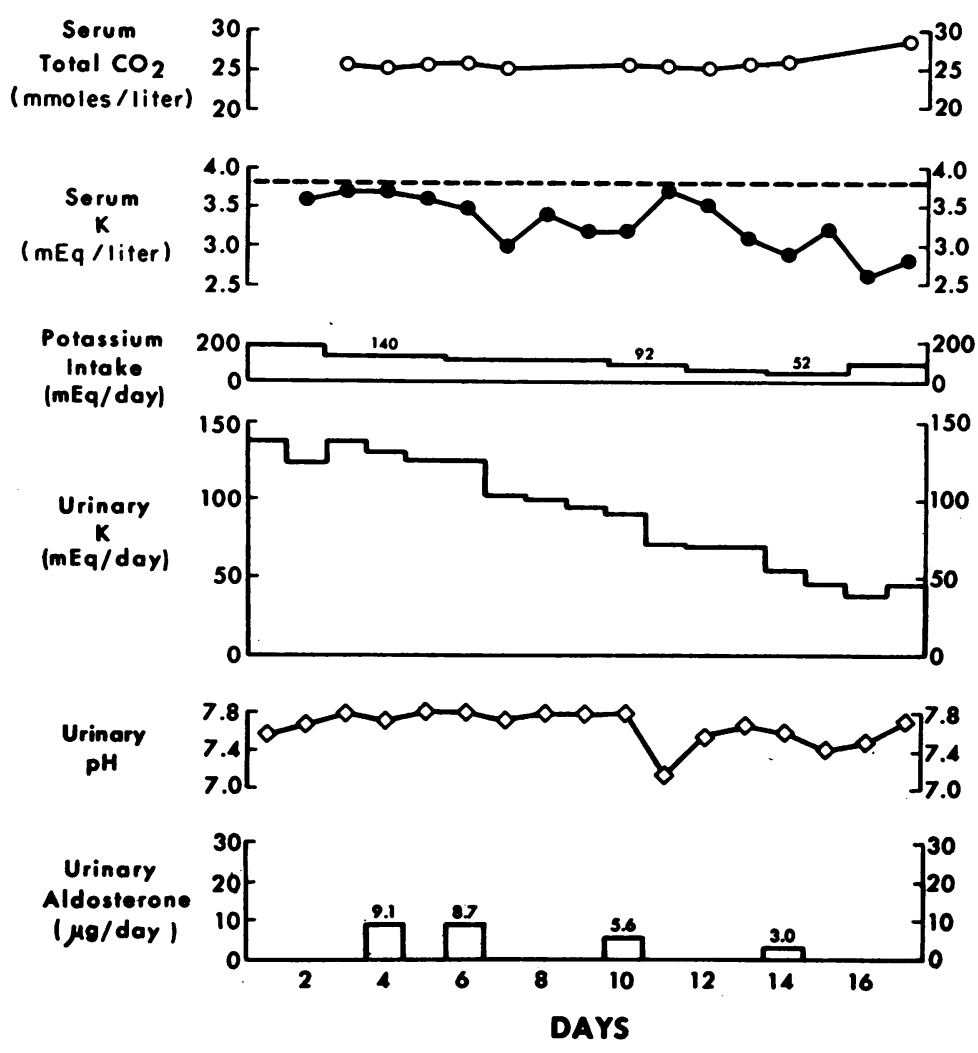

FiguRe 1 Effect of progressively reducing potassium supplements on serum potassium concentration and urinary potassium excretion in a patient with renal tubular acidosis associated with the Fanconi syndrome (M. P.) in whom correction of acidosis was sustained. 


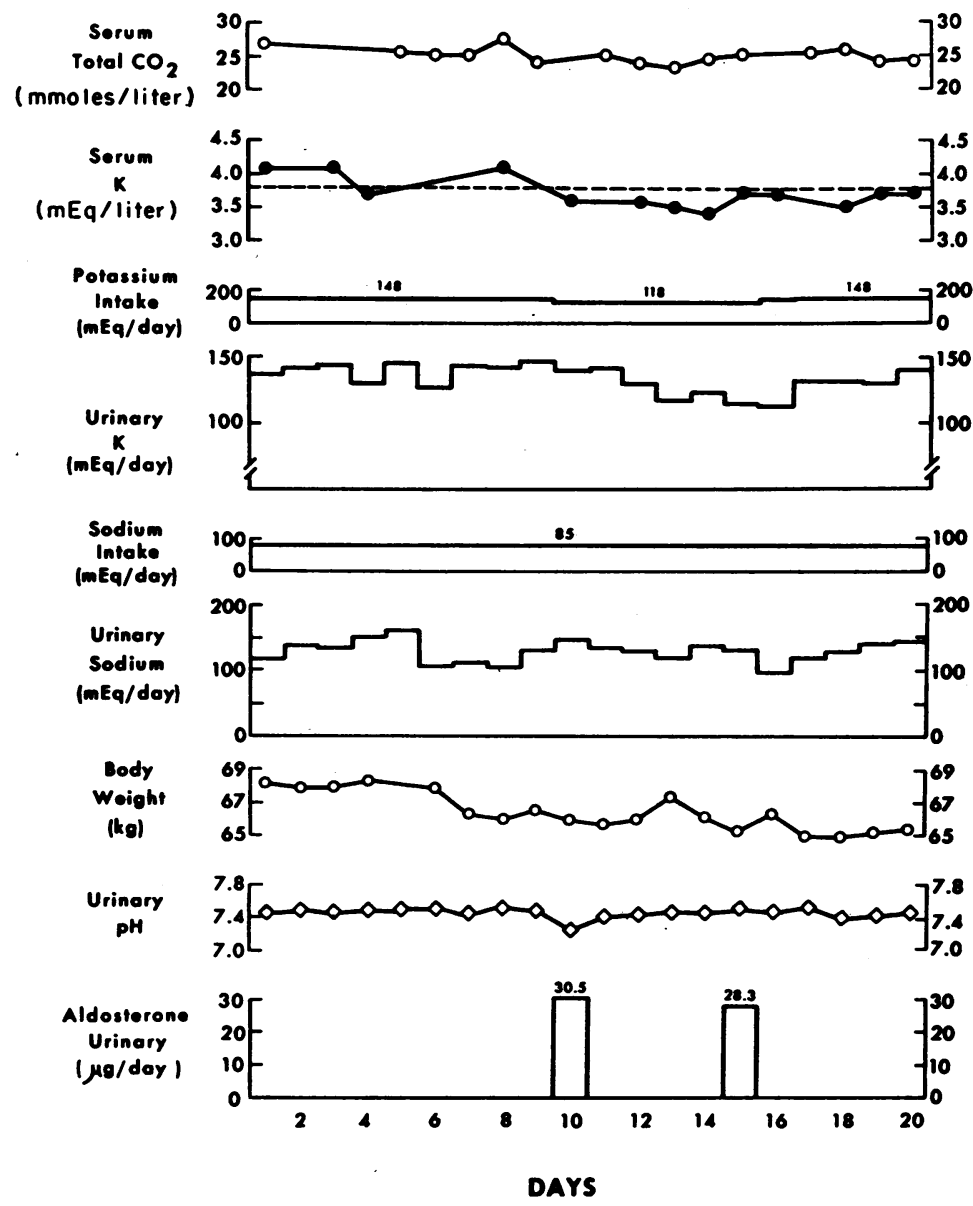

FIGURE 2 Effect of reducing potassium supplements on serum potassium concentration and urinary potassium excretion in a patient with renal tubular acidosis associated with the Fanconi syndrome (R. G.) in whom correction of acidosis was sustained.

magnitude of negative potassium balance appeared to be modest as judged from cumulative urinary losses of potassium. When dietary potassium is restricted in most normal subjects, the occurrence of hypokalemia is less rapid, despite relatively greater cumulative urinary losses of potassium (21-26). But in normal subjects, in contrast to the patients studied with RTA, urinary excretion of potassium decreases to less than $40 \mathrm{mEq} /$ day when hypokalemia occurs, even when it occurs rapidly and despite relatively modest negative potassium balance (27). Moreover, when serum potassium concentration is rapidly reduced experimentally by hemodialysis and changes in arterial $\mathrm{pH}$ and bicarbonate concentration are prevented, the rate of excretion of urinary potassium varies directly with the serum potassium concentration (28). Accordingly, in the presently reported patients with RTA, the inappropriately high urinary excretion rates of potassium during hypokalemia (Fig. 4) indicate impaired renal conservation of potassium.
In each of the first five studies, the urinary $\mathrm{pH}$ was usually equal to or greater than arterial $\mathrm{pH}$ (Figs. 1-3, Table II) or at least greater than the minimal urinary $\mathrm{pH}$ attained during metabolic acidosis (K. E., Tables I and III).

In study 6 (L. C. S.) in which the plasma bicarbonate concentration was progressively increased from 19.2 to $24.1 \mathrm{mmoles} / \mathrm{liter}$ over a period of 19 days, the urinary $\mathrm{pH}$ increased gradually from 6.9 to 7.4 ; urinary potassium decreased slightly, from $46-58 \mathrm{mEq} /$ day to $38-47$ $\mathrm{mEq} / \mathrm{day}$, and the serum potassium concentration increased slightly, from $2.6-2.8 \mathrm{mEq} /$ liter to $2.8-3.0 \mathrm{mEq}$ / liter (Fig. 5). At no time did urinary potassium excretion decrease to rates that could be regarded as appropriately low for the degree of hypokalemia present (cf. Figs. 4 and 5).

24-hr urinary aldosterone was supernormal in R. G. (Fig. 2) and L. C. S. (Figs. 3 and 4, Table II), but was within normal limits in M. P. (Fig. 1), K. E. 
(Table III), and L. C. S. (Fig. 5), compared to the values obtained in normal subjects $(4-17 \mu \mathrm{g} / 24 \mathrm{hr}$ ) on similar sodium intakes. In L. C. S., the rate of excretion of aldosterone was directly related to the serum potassium concentration: When the serum potassium concentration was less than $3.2 \mathrm{mEq} /$ liter, urinary aldosterone varied from 6.4 to $10.0 \mu \mathrm{g} / 24 \mathrm{hr}$ (Figs. 3 and 5, Table II); when the serum potassium concentration was greater than $4.0 \mathrm{mEq} /$ liter, urinary aldosterone varied from 36 to $82 \mu \mathrm{g} / 24 \mathrm{hr}$ (Fig. 3, Table II). In view of the continuous hypokalemia in K. E. (Table III), the value of urinary aldosterone of $16.2 \mu \mathrm{g} / 24 \mathrm{hr}$, while within the normal range, probably can be regarded as abnormally high $(29,30)$.
Whenever measured, plasma volume was within normal limits; study $1: 55 \mathrm{ml} / \mathrm{kg}$ (day 12 ); study 2 : $37 \mathrm{ml} / \mathrm{kg}$ (day 5 ), $38 \mathrm{ml} / \mathrm{kg}$ (day 11 ), $48 \mathrm{ml} / \mathrm{kg}$ (day 20 ) ; study $3: 45 \mathrm{ml} / \mathrm{kg}$ (day 3 ), $47 \mathrm{ml} / \mathrm{kg}$ (day 12 ).

\section{DISCUSSION}

When even minimal degrees of hypokalemia are experimentally induced in normal subjects during short term studies of potassium depletion, urinary excretion of potassium decreases to less than $40 \mathrm{mEq}$ per day (21-27), despite either concomitant metabolic acidosis (21) or mild metabolic alkalosis $(22,27)$ (Fig. 4). Renal potassium wasting can be defined, therefore, as the continued urinary excretion of more than $40 \mathrm{mEq}$ of potassium per
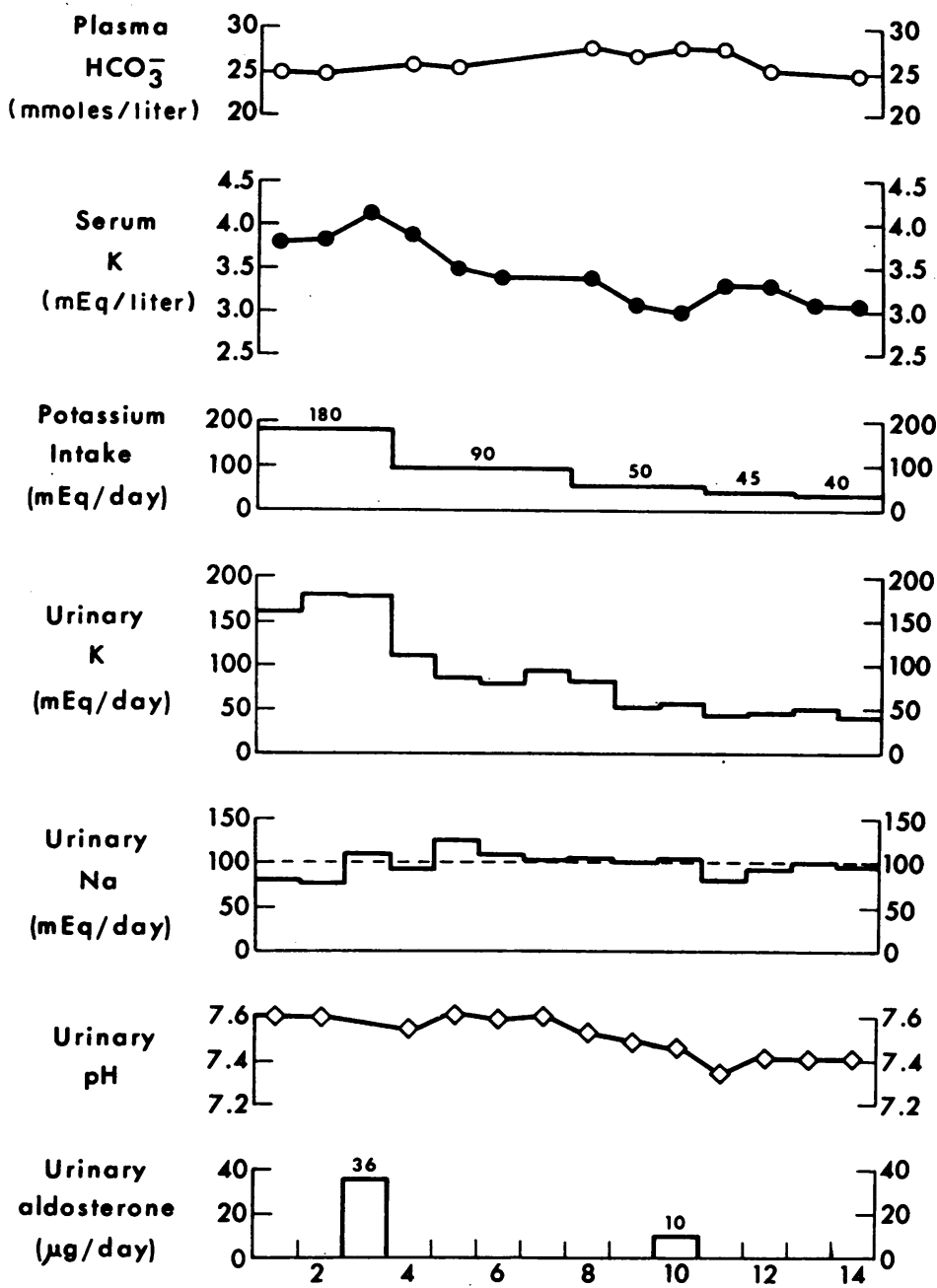

DAYS

FIGURE 3 Effect of progressively reducing potassium supplements on serum potassium concentration and urinary potassium excretion in a patient with classic renal tubular acidosis (L. C. S.) in whom correction of acidosis was sustained. 
TABLE II

Effect of Reduction of Potassium Supplements on Serum Potassium Concentration and Urinary Potassium Excretion during Sustained Correction of Acidosis in a Patient with Classic RTA (L.C.S.)*

\begin{tabular}{|c|c|c|c|c|c|c|c|c|c|c|c|c|c|}
\hline \multirow[b]{2}{*}{ Day } & \multicolumn{2}{|c|}{ Intake } & \multicolumn{4}{|c|}{ Serum } & \multicolumn{5}{|c|}{ Urine } & \multirow[b]{2}{*}{ Cor } & \multirow[b]{2}{*}{$\begin{array}{c}\text { Body } \\
\text { weight }\end{array}$} \\
\hline & $\mathrm{Na}$ & $\mathbf{K}$ & $\mathrm{CO}_{2}$ & $\mathrm{Cl}$ & $\mathrm{Na}$ & $\mathbf{K}$ & $\mathrm{K}$ & $\mathrm{Na}$ & $\mathrm{Cl}$ & $\mathrm{pH}$ & $\begin{array}{l}\text { Aldo- } \\
\text { sterone }\end{array}$ & & \\
\hline & \multicolumn{2}{|c|}{$m E q / d a y$} & $\begin{array}{c}\text { mmoles/ } \\
\text { liter }\end{array}$ & \multicolumn{3}{|c|}{$m E q /$ liter } & \multicolumn{4}{|c|}{$m E q / d a y$} & $\mu g / d a y$ & $m l / m i n$ & kg \\
\hline 1 & 78 & 193 & 25.8 & 105 & 138 & 4.0 & 162 & 67 & 97 & 7.46 & & 107.3 & 38.4 \\
\hline 2 & 78 & 193 & 25.4 & 106 & 139 & 4.3 & 167 & 68 & 100 & 7.43 & 82 & 96.6 & 38.4 \\
\hline 3 & 78 & 193 & 25.1 & 104 & 136 & 4.2 & 156 & 70 & 109 & 7.40 & & 92.0 & 38.0 \\
\hline 4 & 138 & 133 & 26.8 & 102 & 136 & 4.3 & 151 & 98 & 95 & 7.43 & & 102.7 & 38.3 \\
\hline 5 & 138 & 133 & 25.3 & 103 & 136 & 3.6 & 119 & 94 & 91 & 7.59 & & 89.1 & 38.7 \\
\hline 6 & 138 & 133 & & 98 & 138 & 3.5 & 105 & 65 & 70 & 7.46 & & & 38.0 \\
\hline 7 & 138 & 133 & & 102 & 138 & 3.6 & 119 & 104 & 89 & 7.51 & & & 38.6 \\
\hline 8 & 138 & 133 & 24.8 & 100 & 131 & 3.4 & 125 & 176 & 146 & 7.57 & 6 & 99.6 & 38.4 \\
\hline 9 & & & 25.3 & 100 & 136 & 3.6 & & & & & & & 38.0 \\
\hline
\end{tabular}

* Correction of systemic acidosis was sustained by the oral administration in divided doses of 90 mmoles of bicarbonate daily; on day 9 arterial $\mathrm{pH}$ was 7.412 and $\mathrm{PCO}_{2}$ was 42.6.

day in the presence of potassium depletion sufficient to produce hypokalemia $(14,31-35)$. Because in adult subjects dietary potassium usually exceeds $50 \mathrm{mEq}$ per day a mild impairment in renal conservation of potassium may not cause hypokalemia unless potassium intake is reduced to low-normal or slightly subnormal levels (14, $36,37)$. With a more severe impairment in renal conservation of potassium, hypokalemia may occur with normal potassium intake, and a greater than normal intake will be required to correct potassium depletion and maintain normokalemia. For a given degree of impairment in renal conservation of potassium, potassium balance can occur at either normal or subnormal serum potassium concentrations depending on the potassium intake $(36,37)$.

The results of the present studies indicate that both in

TABLE III

Effect of Sustained Correction of Acidosis on Serum Potassium Concentration and Urinary Potassium Excretion in a Patient with Classic RTA (K. E.)*

\begin{tabular}{|c|c|c|c|c|c|c|c|c|c|c|c|c|}
\hline \multirow[b]{2}{*}{ Day } & \multicolumn{3}{|c|}{ Arterial } & \multicolumn{4}{|c|}{ Serum } & \multicolumn{5}{|c|}{ Urine } \\
\hline & $\mathrm{pH}$ & $\mathrm{PcO}_{2}$ & $\mathrm{HCO}_{3}-$ & $\mathrm{CO}_{2}$ & $\mathrm{Cl}$ & $\mathrm{Na}$ & $\mathbf{K}$ & $\mathbf{K}$ & $\mathrm{Na}$ & $\mathrm{Cl}$ & $\begin{array}{l}\text { Creat- } \\
\text { inine }\end{array}$ & $\mathrm{pH}$ \\
\hline & & $\begin{array}{l}m m \\
H_{\mathbf{g}}\end{array}$ & $\begin{array}{c}\text { mmoles/ } \\
\text { liter }\end{array}$ & $\begin{array}{c}\text { mmoles/ } \\
\text { liter }\end{array}$ & & $n E q /$ liter & & & $m E q / d a y$ & & $m g / d a y$ & \\
\hline 1 & & & & & & & & 131 & 94 & 64 & 903 & \\
\hline 2 & & & & 27.4 & 98 & 132 & 3.2 & 136 & 123 & 72 & 957 & \\
\hline 3 & & & & & & & & 104 & 124 & 68 & 837 & \\
\hline 4 & & & & 27.8 & 99 & 129 & 2.9 & 147 & 117 & 65 & 961 & \\
\hline 5 & 7.397 & 42 & 25.2 & 27.7 & 100 & 133 & 3.3 & 122 & 98 & 60 & 882 & \\
\hline 6 & & & & & & & & 126 & 91 & 57 & 874 & \\
\hline 7 & & & & & & & & 130 & 103 & 59 & 834 & 7.32 \\
\hline 8 & 7.403 & 41 & 24.6 & 27.0 & 100 & 128 & 3.1 & 119 & 82 & 50 & 901 & \\
\hline 9 & & & & & & & & 118 & 63 & 45 & 895 & 7.16 \\
\hline $10 \ddagger$ & & & & & & & & 135 & 75 & 49 & 920 & 7.35 \\
\hline 11 & & & & 28.5 & 97 & 131 & 2.6 & 100 & 54 & 52 & 894 & 7.26 \\
\hline 12 & & & & & & & & & & & & \\
\hline 13 & 7.386 & 42 & 24.6 & 28.3 & 102 & 133 & 3.2 & 123 & 70 & 60 & 873 & 7.41 \\
\hline
\end{tabular}

* Correction of systemic acidosis was sustained by the oral administration of 60 mmoles of bicarbonate daily in divided doses.

$\ddagger$ Urinary aldosterone, $16.2 \mathrm{\mu g} / 24 \mathrm{hr}$. 
patients with classic RTA and in patients with RTA associated with the Fanconi syndrome, renal potassium wasting can persist despite sustained correction of systemic acidosis with alkali therapy. In each of the four patients studied, urinary excretion of potassium exceeded $80 \mathrm{mEq}$ per day during sustained hypokalemia. Accordingly, in each patient a normal dietary potassium intake of $50-75 \mathrm{mEq}$ per day was insufficient to maintain normokalemia. In two patients (M. P., R. G.), maintenance of normokalemia required a total potassium intake of more than $115 \mathrm{mEq}$ per day, approximately three times the minimal amount of potassium required to maintain normokalemia in normal subjects. Whenever potassium supplements were reduced, urinary potassium decreased, but never to rates appropriately low for the degree of hypokalemia. When all potassium supplements were discontinued in M. P. and L. C. S., urinary excretion of potassium decreased to rates as low as $40 \mathrm{mEq}$ per day, but only when the serum potassium concentration had decreased to $2.5 \mathrm{mEq}$ per liter (M. P.) and $3.1 \mathrm{mEq}$ per liter (L. C. S.). With similar degrees of hypokalemia in normal subjects, urinary potassium is almost invariably less than $20 \mathrm{mEq}$ per day (Fig. 4).

In classic RTA, renal potassium wasting might be the result of an inability of the renal tubule to establish a normally steep lumen-peritubular $\mathrm{H}^{+}$gradient: According to this hypothesis, the gradient restriction on renal $\mathrm{H}^{+}$secretion reduces the rate of $\mathrm{H}^{+}-\mathrm{Na}^{+}$exchange; $\mathrm{K}^{+}-\mathrm{Na}^{+}$exchange increases reciprocally, and urinary loss of sodium results in sodium depletion and secondary hyperaldosteronism $(4,6,14-18)$. This hypothesis is based on the observation that correction of systemic acidosis with alkali therapy, or the administration of sodium phosphate, can lead to a reduction in urinary excretion of potassium and correction of hypokalemia $(1,2,18)$. By removing the inferred restriction on renal $\mathrm{H}^{+}$secretion, either by increasing urinary $\mathrm{pH}$ to values equal to or greater than arterial $\mathrm{pH}$ (correction of acidosis with alkali therapy) or by increasing urinary titratable buffer anion only (administration of phosphate), $\mathrm{H}^{+}-\mathrm{Na}^{+}$exchange presumably increases, $\mathrm{K}^{+}-\mathrm{Na}^{+}$exchange presumably decreases, and correction of sodium depletion presumably removes the stimulus to hyperaldosteronism (18).

The results of the present studies, however, provide no support for the hypothesis that a gradient restriction on renal $\mathrm{H}^{+}$secretion alone underlies renal potassium wasting in classic RTA. In the two patients with classic RTA studied, renal potassium wasting persisted despite sustained correction of acidosis with alkali therapy, even though urinary $\mathrm{pH}$ was equal to or greater than the normal arterial $\mathrm{pH}$ or was at least greater than the minimal urinary $\mathrm{pH}$ attained during acidosis. Although stepwise correction of acidosis in one of these patients was attended by a stepwise reduction in the urinary ex-

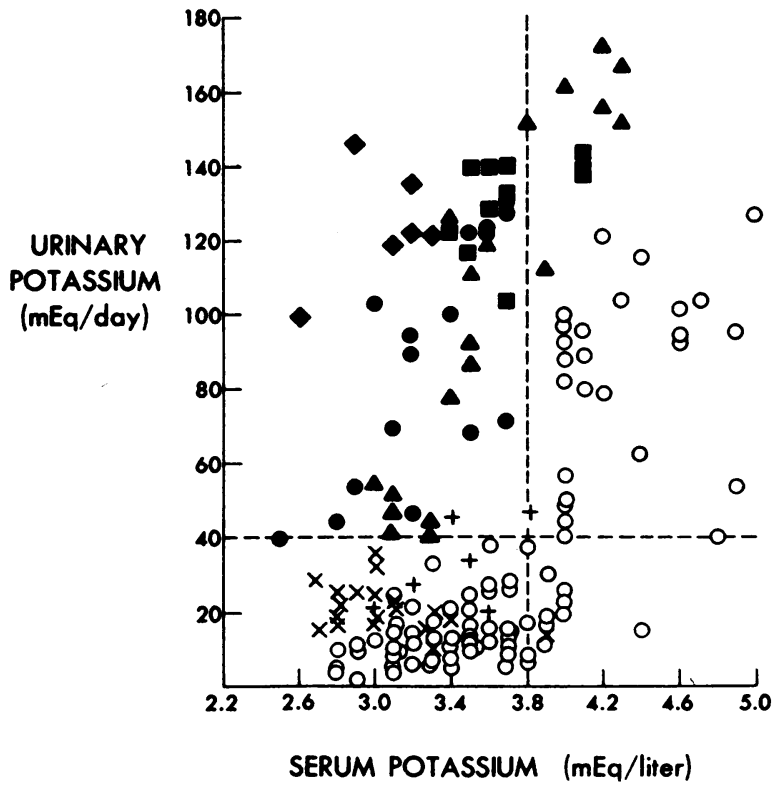

FIGURE 4 Relationship between urinary potassium excretion and serum potassium concentration in patients with renal tubular acidosis in whom correction of acidosis was sustained (closed symbols. Figs. 1-3, Tables II-III) and in normal subjects experimentally depleted of potassium by dietary restriction (open circles, crosses, X's) (21-27). Some of the subjects represented by $\bigcirc$ were mildly alkalotic and were excreting significant amounts of urinary bicarbonate (27); the subjects represented by + were moderately alkalotic and were excreting more than $50 \mathrm{mEq}$ of urinary bicarbonate daily (22); the subjects represented by $X$ were given large amounts of desoxycorticosterone after hypokalemia supervened $(27)$.

cretion of potassium and aldosterone and an increase in the serum potassium concentration, potassium excretion never decreased to values appropriately low for the existing degree of potassium depletion.

The recently reported data of Gill, Bell, and Bartter (18) are the most extensive offered in support of the hypothesis that a gradient restriction on renal $\mathrm{H}^{+}$secretion underlies renal potassium wasting in classic RTA. In four adult patients with seemingly classic RTA, these workers demonstrated that substitution of $100 \mathrm{mEq}$ of sodium in the form of $\mathrm{NaHCO}_{3}$ or $\mathrm{Na}_{2} \mathrm{HPO}_{4}$ for 100 $\mathrm{mEq}$ of $\mathrm{NaCl}$ resulted in a decrease in urinary sodium, potassium and aldosterone, and, in some studies, correction of systemic acidosis and sufficient positive potassium balance to correct hypokalemia. These findings, however, do not exclude the possibility of a persisting defect in renal conservation of potassium. Because the urinary excretion rates of potassium were not reported, it cannot be ascertained whether potassium excretion ever decreased to rates appropriately low for the existing degree of potassium depletion. At the reported levels 

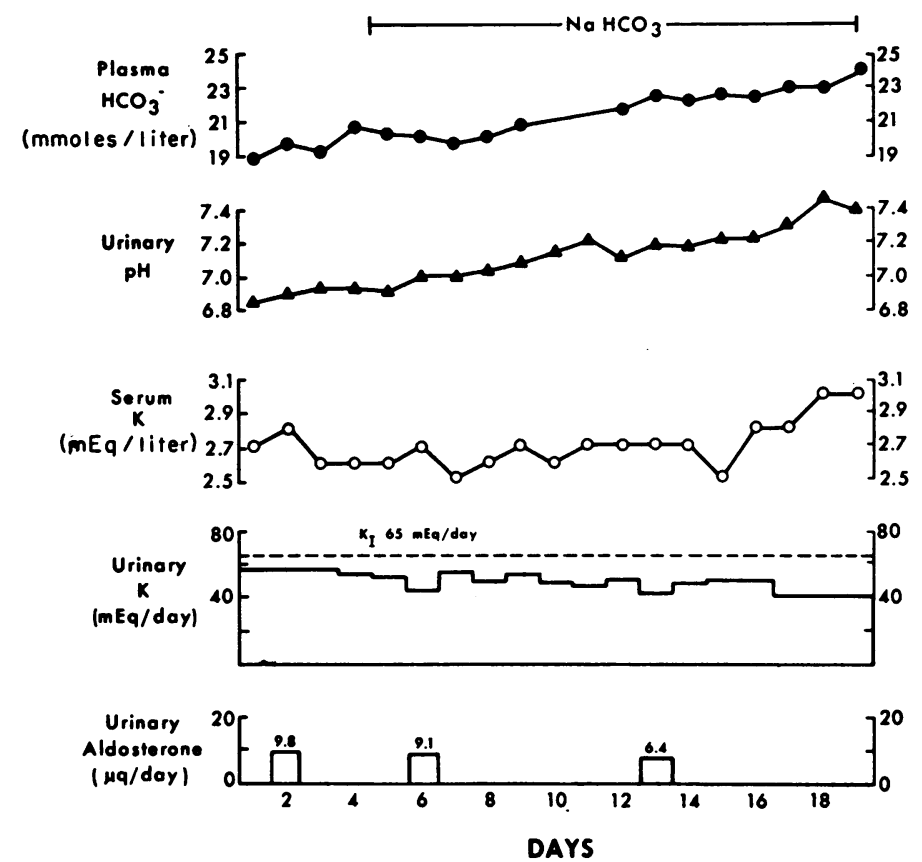

Figure 5 Effect of gradual correction of acidosis on serum potassium concentration and urinary potassium excretion in a patient with classic renal tubular acidosis (L. C. S.).

of potassium intake, which were relatively high in some of the patients studied, correction of hypokalemia might have occurred during alkali therapy with only a modest decrease in urinary potassium excretion. A persistent, if moderate, impairment in renal conservation of potassium might have been demonstrated if dietary potassium intake had been reduced $(14,36,37)$. Such an impairment could differ from that in the presently reported patients only in degree.

In the absence of published evidence that any patients with classic RTA can conserve potassium normally under conditions in which the inferred gradient restriction on renal $\mathrm{H}^{+}$secretion is presumably removed, the presently reported demonstration that some patients continue to waste potassium under such conditions, suggests the possibility that the impairments in renal potassium conservation and in renal acidification are independent functional disorders caused by the same underlying abnormality. The disorder of renal acidification in classic RTA has been variously attributed to abnormalities in the intracellular metabolic processes that provide energy presumed necessary for active $\mathrm{H}^{+}$secretion $(16,38)$ and to structural abnormalities that increase the permeability of the luminal membrane to $\mathrm{H}^{+}$and permit its backdiffusion (6). Conceivably, the same metabolic or structural abnormality of the distal nephron that precludes establishment of appropriately high intraluminal $\mathrm{H}^{+}$con- centrations, could also preclude the establishment of appropriately low intraluminal potassium concentrations, since potassium transport at the luminal membrane of the distal nephron consists of both active reabsorption and passive diffusion from cell to lumen $(39,40)$. Such an independent disorder of renal potassium conservation would in no way exclude the possibility that renal potassium wasting might be in part a reversible consequence of the renal acidification disorder per se.

In two patients with RTA associated with the Fanconi syndrome, the demonstration of renal potassium wasting during sustained correction of acidosis with alkali therapy provides no support for the belief that renal potassium wasting can be corrected in such patients solely by correction of systemic acidosis (17). In fact, in patients with the Fanconi syndrome, correction of acidosis with alkali therapy might be predicted to increase urinary potassium excretion. In these patients, raising the plasma bicarbonate concentration to normal levels has the immediate and sustained effect of swamping the distal nephron with massive amounts of sodium bicarbonate, a consequence of markedly impaired bicarbonate reabsorption in the proximal nephron $(9,41)$. In the presence of a continued stimulus for sodium reabsorption, delivery to the distal nephron of such supernormal amounts of sodium and the relatively impermeant bicarbonate anion would be expected to increase intra- 
luminal negativity and thereby stimulate potassium secretion and promote renal potassium wasting $(39,40$, 42). This possibility is supported by the demonstration in patients with the Fanconi syndrome, that urinary excretion of potassium and bicarbonate increased srikingly and concurrently when the plasma bicarbonate concentration was raised from subnormal to normal levels (41, 43 ), and by the observation that at normal plasma bicarbonate concentrations the severity of renal potassium wasting in such patients varies directly with the urinary excretion rates of sodium and bicarbonate (41).

In the patients with classic RTA, however, the persistence of renal potassium wasting during sustained correction of acidosis could not be attributed to the delivery of massive amounts of sodium bicarbonate to the distal nephron. In these patients, reabsorption of bicarbonate in the proximal nephron cannot be greatly impaired since even at normal plasma bicarbonate concentrations, renal reabsorption of filtered bicarbonate is nearly complete $(4,6,8)$. Moreover, when the plasma bicarbonate concentration is increased from subnormal to normal levels by oral (Fig. 5) or intravenous (41) administration of sodium bicarbonate, urinary bicarbonate excretion increases only slightly and urinary potassium excretion does not increase.

Both in the patients with Fanconi's syndrome and in the patients with classic RTA, the persistence of renal potassium wasting may have resulted in part from continuing hyperaldosteronism. In two patients (R. G., L. C. S.), the urinary excretion rates of aldosterone were clearly supernormal. In the other two patients, the urinary excretion rates of aldosterone were not frankly increased in comparison with the excretion rates observed in normal subjects ingesting similar amounts of sodium. But because both were potassium-depleted when the measurements were made, and because potassium depletion characteristically suppresses aldosterone secretion $(29,30)$, the observed "normal" excretion rates of aldosterone may well have been abnormally high. Since a "normal" secretory rate of aldosterone apparently can sustain renal potassium wasting when potassium depletion is present (44), the persistence of renal potassium wasting in these patients could reflect in part a continuing state of effective hyperaldosteronism. In the patients with Fanconi's syndrome, the effectiveness of hyperaldosteronism in promoting renal potassium wasting is undoubtedly augmented by the delivery to the distal nephron of large amounts of sodium with the relatively impermeant bicarbonate anion. In the patients with classic RTA, even the relatively modest increase in bicarbonate concentration in the distal nephron could, in the presence of at least normal distal delivery of sodium, potentiate the kaliuretic effect of hyperaldosteronism.
Conceivably, alkali therapy may correct renal potassium wasting in patients with classic RTA only when it also leads to correction of their hyperaldosteronism.

The cause of continuing hyperaldosteronism during sustained correction of acidosis in these patients is not defined by the present studies. None of the patients was hypertensive. It might be argued that the patients were sodium depleted at the time of study because sodium bicarbonate therapy had not been sufficiently prolonged to correct sodium deficits incurred during acidosis. In each of the patients, however, correction of acidosis had been sustained for at least 2 months when the studies were begun, and their plasma volumes were not measurably reduced. Moreover, if sodium depletion were present, it could not be ascribed to a foreshortened period of positive sodium balance because the urinary excretion rates of sodium approximated (Fig. 3) or exceeded (Fig. 2) sodium intake. Conceivably, renal sodium wasting persisted despite sustained correction of acidosis. In patients with classic RTA renal sodium wasting would not be predicted to persist if, as generally supposed, it occurs solely as the consequence of a gradient restriction on renal $\mathrm{H}^{+}-\mathrm{Na}^{+}$exchange (18). To our knowledge, however, the ability of patients with classic RTA to conserve sodium has not been evaluated during dietary restriction of sodium and sustained correction of acidosis. Accordingly, a disorder of renal sodium reabsorption, independent from that of renal acidification, has not been excluded in classic RTA. If severe enough, such a disorder presumably could result in continued sodium depletion despite a normal sodium intake. In patients with RTA and Fanconi's syndrome, renal wasting of sodium during sustained correction of acidosis would not be surprising. Moreover, at sustained normal plasma bicarbonate concentrations in these patients, the continuing delivery of massive amounts of sodium and bicarbonate to the distal nephron $(9,41)$ might give rise to the following sequence: increased concentration of sodium at the macula densa $(45,46)$, increased release of renin by the juxtaglomerular cells (47), increased production of angiotensin, and increased secretion of aldosterone.

When potassium supplements were reduced in the patients studied, hypokalemia occurred rapidly with only a modest cumulative urinary loss of potassium. When potassium is restricted in normal subjects, the serum potassium concentration decreases relatively slowly, not because near maximal renal conservation of potassium occurs promptly, but because the amount of potassium lost from the extracellular fluid is almost balanced by the amount of potassium transferred into the extracellular fluid from intracellular stores. If net movement of potassium out of cells into the extracellular fluid did not occur, the amount of potassium excreted in the urine 
during the first $24 \mathrm{hr}$ would, in most instances, nearly exhaust the extracellular fluid of its relatively modest potassium content. But with prolonged hyperaldosteronism, as in the patients of the present study, the largest intracellular store of mobilizable potassium, skeletal muscle, may be substantially depleted of potassium, even though extracellular potassium concentration is maintained at normal levels with potassium supplements (48). Accordingly, reduction of potassium supplements might result in rapidly occurring hypokalemia with only modest cumulative urinary losses of potassium.

Rapidly occurring hypokalemia may dictate the occurrence of only modest cumulative urinary loss of potassium, even in patients with renal potassium wasting. Rapid reductions in serum potassium concentration are predictably attended by immediate and striking reductions in urinary potassium excretion $(28,49-53)$ in a variety of experimental and clinical conditions in which known stimuli to net renal secretion of potassium can be presumed to be not increasing. In normal dogs rapidly rendered hypokalemic by hemodialysis, with but minimal external loss of potassium and no measured changes in systemic acid-base equilibrium (28), and in patients with periodic paralysis and rapidly occurring hypokalemia and no external loss of potassium (49-52), urinary potassium excretion decreases rapidly and strikingly when hypokalemia occurs, the excretion rate of potassium varying directly with the serum potassium concentration. In patients with severe and continuing potassium depletion (laxative abuse) in whom hypokalemia was transiently corrected with small amounts of potassium, Antoine and Patte (53) found that the urinary excretion rate of potassium varied directly with and was highly correlated with serum potassium concentration. When the administration of potassium was discontinued, hypokalemia recurred rapidly and urinary excretion of potassium decreased promptly and strikingly such that the cumulative urinary loss of potassium was only modest. It would appear then that whenever reduction of potassium intake leads to the occurrence of hypokalemia, the magnitude of the cumulative urinary loss of potassium that occurs depends critically on, and varies directly with, the extent to which the occurrence of hypokalemia is delayed by the net movement of potassium out of intracellular stores. To the extent that prolonged hyperaldosteronism acts to deplete the intracellular stores of mobilizable potassium, it acts to accelerate the occurrence of hypokalemia when potassium is restricted but to limit the cumulative urinary loss of potassium. To the extent that a reduction of aldosterone secretion (from supernormal values) attends the reduction of serum potassium, such a reduction might act to allow partial replenishment of intracellular stores of potassium; hence, net movement of potassium out of cells might be further curtailed and further reduction of serum potassium concentration accelerated. To the extent that hyperaldosteronism contributes to renal potassium wasting, any reduction of aldosterone secretion attending reduction of serum potassium concentration would tend to mitigate renal potassium wasting and thereby also limit the cumulative urinary loss of potassium.

\section{ACKNOWLEDGMENTS}

We gratefully acknowledge our debt to Dr. Edward G. Biglieri, San Francisco General Hospital, for the measurements of urinary aldosterone and for several valuable discussions. We thank Dr. Ralph Alexander for referring patient R. G., Dr. Erwin J. Henning for referring patient K. E., Dr. Felix O. Kolb for referring patient L. C. S., and Dr. Ralph O. Wallerstein for referring patient M. P.

These studies were supported by U. S. Public Health Service Grants HE-10044, HD00182, and CA 11067; by Cancer Research Coordinating Committee Funds and School of Medicine Edwards Fund, University of California, San Francisco; and by a grant from the California Division of the American Cancer Society. Studies were carried out on the General Clinical Research Center Ward, University of California, San Francisco, with funds provided by the Division of Research Resources, RR-79, U. S. Public Health Service.

\section{REFERENCES}

1. Albright, F., and E. C. Reifenstein, Jr. 1948. The Parathyroid Glands and Metabolic Bone Disease. The Williams \& Wilkins Company, Baltimore, Md. 227.

2. Pines, K. L., and G. H. Mudge. 1951. Renal tubular acidosis with osteomalacia. Report of three cases. Amer. J. Med. 11: 302 .

3. Milne, M. D., S. W. Stanbury, and A. E. Thomson. 1952. Observations on the Fanconi syndrome and renal hyperchloraemic acidosis in the adult. Quart. J. Med. 21: 61 .

4. Reynolds, T. B. 1958. Observations on the pathogenesis of renal tubular acidosis. Amer. J. Med. 25: 503.

5. Wrong, O., and H. E. F. Davies. 1959. The excretion of acid in renal disease. Quart. J. Med. 28: 259.

6. Seldin, D. W., and J. D. Wilson. 1966. Renal tubular acidosis. In The Metabolic Basis of Inherited Disease. J. B. Stanbury, J. B. Wyngaarden, and D. S. Fredrickson, editors. McGraw-Hill Book Company, New York. 1230.

7. Soriano, J. R., and C. M. Edelmann, Jr. 1969. Renal tubular acidosis. Annu. Rev. Med. 20: 363.

8. Morris, R. C., Jr. 1969. Renal tubular acidosis: mechanisms, classification and implications. N. Engl. J. Med. 281: 1405 .

9. Morris, R. C., Jr. 1968. An experimental renal acidification defect in patients with hereditary fructose intolerance. II. Its distinction from classic renal tubular acidosis; its resemblance to the renal acidification defect associated with the Fanconi syndrome of children with cystinosis. J. Clin. Invest. 47: 1648.

10. Worthen, H. G., and R. A. Good. 1958. The de ToniFanconi syndrome with cystinosis: clinical and metabolic study of two cases in a family and a critical re- 
view on the nature of the syndrome. Amer. J. Dis. Child. 95: 653 .

11. Bickel, H., W. C. Smallwood, J. M. Smellie, and E. M. Hickmans. 1952. Cystine storage disease with aminoaciduria and dwarfism (Lignac-Fanconi disease). III. Clinical description, factual analysis, prognosis and treatment of Lignac-Fanconi disease. Acta Paediat. Scand. 42 Suppl. 90: 27.

12. Sirota, J. H., and D. Hamerman. 1954. Renal function studies in an adult subject with the Fanconi syndrome. Amer. J. Med. 16: 138.

13. Fourman, P., and R. A. McCance. 1955. Tetany complicating the treatment of potassium deficiency in renal acidosis. Lancet. 1: 329.

14. Mahler, R. F., and S. W. Stanbury. 1956. Potassiumlosing renal disease. Renal and metabolic observations on a patient sustaining renal wastage of potassium. Quart. J. Med. 25: 21.

15. Milne, M. D. 1963. Renal tubular dysfunction. In Diseases of the Kidney. M. B. Strauss, and L. G. Welt, editors. Little, Brown and Company, Boston, Mass. 786.

16. Relman, A. S. 1964. Renal acidosis and renal excretion of acid in health and disease. Advan. Intern. Med. 12: 295.

17. Leaf, A. 1966. The syndrome of osteomalacia, renal glycosuria, aminoaciduria, and increased phosphorus clearance (the Fanconi syndrome). In The Metabolic Basis of Inherited Disease. J. B. Stanbury, J. B. Wyngaarden, and D. S. Fredrickson, editors. McGraw-Hill Book Company, New York. 2nd edition. 1205.

18. Gill, J. R., Jr., N. H. Bell, and F. C. Bartter. 1967. Impaired conservation of sodium and potassium in renal tubular acidosis and its correction by buffer anions. Clin. Sci. (London). 33: 577.

19. Morris, R. C., Jr. 1968. An experimental renal acidification defect in patients with hereditary fructose intolerance. I. Its resemblance to renal tubular acidosis. J. Clin. Invest. 47 : 1389.

20. Morris, R. C., Jr., and H. H. Fudenberg. 1967. Impaired renal acidification in patients with hypergammaglobulinemia. Medicine (Baltimore). 46: 57.

21. Fourman, P. 1952. The ability of the normal kidney to conserve potassium. Lancet. 1: 1042.

22. Black, D. A. K., and M. D. Milne. 1952. Experimental potassium depletion in man. Clin. Sci. (London). 11: 397.

23. Blahd, W. H., and S. H. Bassett. 1953. Potassium deficiency in man. Metab. (Clin. Exp.). 2: 218.

24. Evans, B. M., N. C. Hughes Jones, M. D. Milne, and S. Steiner. 1954. Electrolyte excretion during experimental potassium depletion in man. Clin. Sci. (London). 13: 305 .

25. Womersley, R. A., and J. H. Darragh. 1955. Potassium and sodium restriction in the normal human. J. Clin. Invest. 34: 456.

26. Squires, R. D., and E. J. Huth. 1959. Experimental potassium depletion in normal human subjects. I. Relation of ionic intakes to the renal conservation of potassium. J. Clin. Invest. 38 : 1134.

27. Huth, E. J., R. D. Squires, and J. R. Elkinton. 1959. Experimental potassium depletion in normal human subjects. II. Renal and hormonal factors in the development of extracellular alkalosis during depletion. J. Clin. Invest. 38: 1149.
28. Siegel, R. R., and W. D. Lotspeich. 1965. Potassium and sodium excretion and potassium homeostasis during acute hypokalemia. Amer. J. Physiol. 208: 1143.

29. Gann, D. S., C. S. Delea, J. R. Gill, Jr., J. P. Thomas, and F. C. Bartter. 1964. Control of aldosterone secretion by change of body potassium in normal man. Amer. J. Physiol. 207: 104.

30. Cannon, P. J., R. P. Ames, and J. H. Laragh. 1966. Relation between potassium balance and aldosterone secretion in normal subjects and in patients with hypertensive or renal tubular disease. J. Clin. Invest. 45: 865.

31. Brooks, R. V., R. R. McSwiney, F. T. G. Prunty, and F. B. Y Wood. 1957. Potassium deficiency of renal and adrenal origin. Amer. J. Med. 23: 391.

32. Gerstein, A. R., S. S. Franklin, C. R. Kleeman, M. H. Maxwell, and E. M. Gold. 1969. Potassium losing pyelonephritis. Arch. Intern. Med. 123: 55.

33. Lauler, D. P. 1966. Preoperative diagnosis of primary aldosteronism. Amer. J. Med. 41: 855.

34. Epstein, F. H., and J. P. Merrill. 1970. Chronic renal failure. In Harrison's Principles of Internal Medicine. 6th edition. M. M. Wintrobe, G. W. Thorn, R. D. Adams, I. L. Bennett, Jr., E. Braunwald, K. J. Isselbacher, and R. G. Petersdorf, editors. McGraw-Hill Book Company, New York, 1393.

35. Lauler, D. P., G. H. Williams, and G. W. Thorn. 1970. Diseases of the adrenal cortex. In Harrison's Principles of Internal Medicine, 6th edition. M. M. Wintrobe, G. W. Thorn, R. D. Adams, I. L. Bennett, Jr., E. Braunwald, K. J. Isselbacher, and R. G. Petersdorf, editors. McGraw-Hill Book Company, New York, 477.

36. Ferris, T., M. Kashgarian, H. Levitin, I. Brandt, and F. H. Epstein. 1961. Renal tubular acidosis and renal potassium wasting acquired as a result of hypercalcemic nephropathy. N. Engl. J. Med. 265: 924.

37. Ferris, T. F., H. Levitin, E. T. Phillips, and F. H. Epstein. 1962. Renal potassium wasting induced by vitamin D. J. Clin. Invest. 41: 1222.

38. Elkinton, J. R. 1962. Hydrogen ion turnover in health and in renal disease. Ann. Intern. Med. 57: 660 .

39. Malnic, G., R. M. Klose, and G. Giebisch. 1964. Micropuncture study of renal potassium excretion in the rat. Amer. J. Physiol. 206: 674.

40. Malnic, G., R. M. Klose, and G. Giebisch. 1966. Micropuncture study of distal tubular potassium and sodium transport in rat nephron. Amer. J. Physiol. 211: 529.

41. Sebastian, A., E. McSherry, and R. C. Morris, Jr. 1971. On the mechanism of renal potassium wasting in renal tubular acidosis associated with the Fanconi syndrome (type 2 RTA). J. Clin. Invest. 50: 231.

42. Clapp, J. R., F. C. Rector, Jr., and D. W. Seldin. 1962. Effect of unreabsorbed anions on proximal and distal transtubular potentials in rats. Amer. J. Physiol. 202: 781.

43. Sebastian, A., E. Morris, I. Ueki, and R. C. Morris, Jr. 1969. On the mechanism of renal potassium wasting in patients with renal tubular acidosis. J. Clin. Invest. 48: 76a (Abstr.)

44. Biglieri, E. G., P. E. Slaton, Jr., S. J. Kronfield, and J. B. Deck. 1967. Primary aldosteronism with unusual secretory pattern. J. Clin. Endocrinol. Metab. 27: 715.

45. Morris, R. C. Jr., E. McSherry, J. F. Kranhold, and A. Sebastian. 1970. Modulation of proximal and distal 
tubule function in Fanconi's syndrome. Birth Defects: Original Article Series. 6: 22.

46. Rosin, J. M., M. A. Katz, R. C. Rector, Jr., and D. W. Seldin. 1970. Acetazolamide in studying sodium reabsorption in diluting segment. Amer. J. Physiol. 219: 1731.

47. Thurau, K. 1966. Influence of sodium concentration at macula densa cells on tubular sodium load. Ann. N.Y. Acad. Sci. 139: 388.

48. Adler, S. 1970. An extrarenal action of aldosterone on mammalian skeletal muscle. Amer. J. Physiol. 218: 616.

49. Ferrebee, J. W., M. K. Garrity, D. W. Atchley, and R. F. Loeb. 1940. Behavior of electrolytes in familial periodic paralysis. Arch. Neurol. Psychiat. 44: 830.

50. Danowski, T. S., J. R. Elkinton, B. A. Burrows, and
A. W. Winkler. 1948. Exchanges of sodium and potassium in familial periodic paralysis. J. Clin. Invest. 27: 65.

51. Conn, J. W., S. S. Fajans, L. H. Louis, D. H. P. Streeten, and R. D. Johnson. 1957. Intermittent aldosteronism in periodic paralysis: dependence of attacks on retention of sodium, and failure to induce attacks by restriction of dietary sodium. Lancet. 1: 802.

52. Streeten, D. H. P. 1966. Periodic paralysis. In Metabolic Basis of Inherited Disease. 2nd edition. J. B. Stanbury, J. B. Wyngaarden, and D. S. Fredrickson, editors. McGraw-Hill Book Company, New York. 905.

53. Antoine, B., and Patte. 1969. Etudes sur les déficits chroniques de potassium chez l'homme. I. Influence des variations rapides de la kaliemie sur le debit urinaire du potassium. Rev. Fr. Etud. Clin. Biol. 14: 984. 